\title{
Dose escalation using ultra-high dose IMRT in intermediate risk prostate cancer without androgen deprivation therapy: preliminary results of toxicity and biochemical control
}

\author{
Maria Grazia Petrongari ${ }^{1 *}$, Valeria Landoni², Biancamaria Saracino ${ }^{1}$, Sara Gomellini ${ }^{1}$, Stefano Arcangeli ${ }^{1}$, \\ Giuseppe laccarino ${ }^{2}$, Paola Pinnarò ${ }^{1}$, Giorgio Arcangeli ${ }^{1}$ and Lidia Strigari ${ }^{2}$
}

\begin{abstract}
Background: To investigate the feasibility of dose escalation (86 Gy at 2 Gy/fraction) with intensity modulated radiation therapy (IMRT) in intermediate-risk prostate cancer without androgen deprivation therapy.

Methods: Patients with histologically proven adenocarcinoma of the prostate, intermediate prognostic category, were enrolled in this study. Early and late toxicity were scored according to the Cancer Therapy Evaluation Program, Common Terminology Criteria for Adverse Events, Version 3.0. Treatment outcome was stated in terms of biochemical failure, biopsy result and clinical failure.
\end{abstract}

Results: 39 patients with a median follow-up of 71 months were analyzed. No patient experienced G3 or G4 acute gastrointestinal (Gl) or genitourinary (GU) toxicity. G2 acute Gl and GU toxicity were observed in $17(44 \%)$ and 20 (51\%) patients, respectively. Fourteen patients (36\%) did not experience acute Gl toxicity and 4 patients (10\%) did not experience acute GU toxicity. G2 late Gl bleeding occurred in 7 of 39 patients (18\%). Both G3 and G4 late Gl toxicity were seen only in one patient (2.5\%). Two patients (5\%) experienced G2 late GU toxicity, while G3 late GU toxicity occurred in 3 patients (8\%). The 5 -year actuarial freedom from biochemical failure (FFBF) was $87 \%$.

Thirty-four patients (87\%) did not show biochemical relapse. Seventeen patients (44\%) underwent biopsy two year after radiotherapy; of these only two were non-negative and both did not show evidence of biochemical disease.

Conclusions: IMRT treatment of patients with localized intermediate-risk prostate cancer at high dose levels without using androgen deprivation therapy (ADT) seems to give good disease control. Nevertheless, future trials should aim at further decreasing toxicity by exploiting image guidance techniques and by reducing the dose delivered at the interface between organs at risk and prostate.

Keywords: Prostate cancer, Intermediate risk, Dose escalation, Absence of ADT, Toxicity, Outcome

\section{Introduction}

The use of dose escalation in radiation therapy, with doses ranging from 74 to $80 \mathrm{~Gy}$, has shown an improvement in the outcome of prostate cancer when compared with conventional doses, as reported in large retrospective studies $[1,2]$ and in some prospective randomized trials [3-8]. Moreover, the dose-response curve of prostate

\footnotetext{
* Correspondence: petrongari@ifo.it

${ }^{1}$ Department of Radiation Oncology, Regina Elena National Cancer Institute, Rome, Italy

Full list of author information is available at the end of the article
}

cancer showed an optimal disease control in the region of ultra-high dose levels ( $\geq 80$ Gy) [9]. As a matter of fact, dose escalation has improved distant metastasisfree survival (DMFS) and cancer-specific survival (CSS) [10-13]. However, the use of three-dimensional conformal radiation therapy (3D-CRT) for dose escalation is limited by side effects [3-7,14]; while intensity-modulated radiation therapy (IMRT) generally decreases treatmentrelated morbidity by producing steeper dose-gradients [13,15-17]. At MSKCC [17,18] the feasibility of dose escalation from 81 Gy to 86.4 Gy at $1.8 \mathrm{~Gy} /$ fraction in 
localized prostate cancer in association with short course Androgen Deprivation Therapy (ADT) has been investigated, suggesting that ultra-high dose regimen is well tolerated and reporting an excellent biochemical control. However the role and the optimal duration of ADT with dose escalated radiation therapy still remains controversial.

The aim of our paper is to report the outcome of a dose-escalation study with an ultra-high dose of 86 Gy at $2 \mathrm{~Gy} /$ fraction with IMRT technique in intermediaterisk prostate cancer patients, without the use of ADT, in terms of toxicity and biochemical control.

\section{Methods}

This is a single institution prospective phase II study approved by Regina Elena National Cancer Institute, Ethical Committee. Patients enrolled in the study belonged to the intermediate prognostic category according to the National Comprehensive Cancer Network classification system (www.nccn.com) which included patients with stage T2b-T2c tumors, and PSA $>10 \mathrm{ng} / \mathrm{ml}$ but $\leq 20 \mathrm{ng} / \mathrm{ml}$, and Gleason score 7. The clinical characteristics of patients and tumors are shown in Table 1.

Inclusion criteria were: 1 ) age $<80$ years; 2) histological proof of prostate adenocarcinoma at intermediate risk; 3 ) risk of lymph node involvement $<15 \%$, according to Roach formula, or absence of adenopathy assessed by

\section{Table 1 Clinical characteristics of patients and tumor} staging

\begin{tabular}{|c|c|c|}
\hline \multicolumn{3}{|l|}{ Age (years) } \\
\hline & Median (range) & $72(53-77)$ \\
\hline \multicolumn{3}{|c|}{ Follow-up (mos) } \\
\hline & Median (range) & 71 (32.8-93.6) \\
\hline \multicolumn{3}{|c|}{ Stage (N /\%) } \\
\hline & $\mathrm{T} 1 \mathrm{C}$ & $1(2.5 \%)$ \\
\hline & $\mathrm{T} 2 \mathrm{a}$ & $11(28 \%)$ \\
\hline & $\mathrm{T} 2 \mathrm{~b}$ & $15(38.5 \%)$ \\
\hline & $\mathrm{T} 2 \mathrm{C}$ & $12(31 \%)$ \\
\hline \multicolumn{3}{|c|}{ Gleason score } \\
\hline & $<=6$ & $13(33.3 \%)$ \\
\hline & $7(3+4)$ & $20(51.3 \%)$ \\
\hline & $7(4+3)$ & $6(15.4 \%)$ \\
\hline \multicolumn{3}{|c|}{ \% Biopsy core } \\
\hline & $0-24 \%$ & 12 (31\%) \\
\hline & $25-49 \%$ & $16(41 \%)$ \\
\hline & $50-74 \%$ & $10(26 \%)$ \\
\hline & $75-100 \%$ & $1(2 \%)$ \\
\hline \multicolumn{3}{|l|}{ iPSA } \\
\hline & $<10$ & 37 (95\%) \\
\hline & 10-19.9 & $2(5 \%)$ \\
\hline
\end{tabular}

CT and/or MRI; 4) WHO performance status $<2$; 5) no previous pelvic radiotherapy; 6 ) no previous prostate surgery; 7) no previous hormonal therapy; 8) no previous malignant tumors, with the exception of adequately treated cutaneous carcinomas; 9) declared availability to comply with the planned follow-up examinations; 10) written informed consent. All patients were free of ADT treatment. Written informed consent was signed by all patients. Patients underwent a CT simulation in the prone position by using a customized device for immobilization. A CT scan was performed at $5 \mathrm{~mm}$ intervals from L4/L5 to $5 \mathrm{~cm}$ below the ischial tuberosities. Patients were asked to void the rectum before simulation and before each treatment session, also with the use of glycerine suppositories or enemas. The bladder had to be taken at middle filling by voiding it 1.5 hours before simulation and daily before each treatment session. The acquired images were then transferred to the Eclipse (v.8.9) treatment planning system. The clinical target volume (CTV) consisted of the prostate and entire seminal vesicles, the planning target volume (PTV) was obtained by adding $1 \mathrm{~cm}$ margin in all directions except toward the rectum, where the margin was reduced to $0.6 \mathrm{~cm}$ according to our institutional policy [19]. The rectal and bladder walls were contoured as critical normal structures, in particular, the rectum was outlined from the sigmoid flexure to the anal margin. Patients were treated with a 15 MV five-field sliding window IMRT technique. The beam arrangement was: posterior $\left(0^{\circ}\right)$, right posterior oblique $\left(75^{\circ}\right)$, right anterior oblique $\left(135^{\circ}\right)$, left anterior oblique $\left(225^{\circ}\right)$ and left posterior oblique $\left(285^{\circ}\right)$. Plans were optimized to give at least $95 \%$ and $90 \%$ of the prescribed dose to CTV and PTV, respectively. The maximum dose heterogeneity within the PTV was set at $17 \%$ (from $90 \%$ to 107\%). No constraints were applied to the overlapping volume between the PTV and rectum, which was treated as PTV. Dose-volume constraints were set for rectal and bladder walls and femoral heads. Dose-volume constraints were: maximum 70 Gy, 50 Gy and 40 Gy to $30 \%, 50 \%$ and $60 \%$ of the rectal wall volume, respectively, maximum 70 Gy and 50 Gy to $50 \%$ and $70 \%$ of the bladder wall volume, respectively, and maximum 55 Gy to $70 \%$ of the femoral heads. The normal tissue planning limits were based on our prior experience and on previously published studies [20-25]. Dose-volume histograms were recorded for all patients. Patients were treated with Varian 2100 linear accelerators (Varian Associates, Palo Alto, CA) equipped with 120-leaf multi-leaf collimators. The accuracy of the set-up was monitored daily by verifying the position of the isocenter comparing skeletal landmarks on orthogonal portal images acquired with an electronic portal imaging device (EPID) to the digitally reconstructed radiography (DRRs). 


\section{Study endpoints}

The primary endpoint of our study was gastrointestinal (GI) and genitourinary (GU) toxicity. Early and late toxicity data were scored according to the Cancer Therapy Evaluation Program, Common Terminology Criteria for Adverse Events, Version 3.0 [26]. Grade 1-4: Grade 1 (mild) - asymptomatic or mild symptoms requiring only clinical or diagnostic observation; Grade 2 (moderate) minimal, local or noninvasive intervention indicated; Grade 3 (severe) - severe or medically significant but not immediately life-threatening requiring hospitalization, prolonging hospitalization or affecting activities of daily living; Grade 4- life-threatening consequences requiring urgent intervention. Acute side effects occurred during the course of radiation or within 90 days of its completion. Late toxicity was defined as rectal or urinary symptoms occurring or persisting 6 months or more after completing radiotherapy. The secondary endpoints were biochemical failure, biopsy result and clinical failure. The freedom from biochemical failure (FFBF) was defined as the time interval from the first day of radiotherapy to the biochemical relapse, the scores are according to the most recent Phoenix definition of nadir PSA $+2 \mathrm{ng} / \mathrm{ml}$ [27]. The histological diagnosis of the prostate biopsy at 2-years post-radiotherapy was classified as positive (prostatic adenocarcinoma without typical radiation-induced changes), negative (no evidence of carcinoma) or indeterminate (severe treatment effects).

\section{Baseline and follow-up}

All patients were prostate adenocarcinoma pre-treatment biopsy proven. Baseline staging was assessed by initial PSA (iPSA) levels, digital rectal examination (DRE), transrectal ultrasound images, abdomino-pelvic CT, chest RX/CT and bone scan. At baseline, patients were asked to answer questions about their urinary symptoms according to the International Prostate Symptoms Score (IPSS) questionnaire [28]. Patients were monitored weekly during the course of radiotherapy, after 2 and 6 months from the end of the treatment, and then every six months until the second year of follow-up. Afterwards patients were monitored annually. PSA evaluation and DRE were performed at each follow-up visit and a report was drafted, with special emphasis on treatment-related morbidity, which recorded the worst toxicity score for each patient. In case of an increased PSA and/or suspected clinical local relapse (new or increasing palpable prostate nodule) or distant failure (bone pain, low extremity edema, unjustified dyspnea, etc.), the usual diagnostic imaging procedures or prostate biopsies were carried out. All patients underwent a sextant prostate re-biopsy after at least 2 years after the radiation treatment.

\section{Statistical analysis}

For all measured endpoints, patients were censored at the time of the specific event. Actuarial curves of the length of time until late toxicity or biochemical failure were calculated by the Kaplan-Meier product-limit method. All times were calculated from the first day of radiotherapy. Differences between dosimetric parameters between groups were evaluated by a Mann-Whitney test.

\section{Results}

\section{Patients and dosimetry}

From January 2005 to April 201039 patients with histologically proven adenocarcinoma of the prostate were enrolled in an IMRT dose escalation protocol with a total dose of 86 Gy in 43 fractions. The rate of accrual was limited by the inclusion criteria of freedom from ADT. The median follow-up for the cohort was 71 months (range 32.8-93.6 months) and the median age was 71.5 years (range 52.5-77.4 yrs). On average, 99.9\% (standard deviation $0.1 \%$ ) of the PTV volume received at least 77.5 Gy (V100), and 95\% of the PTV volume (D95) received an average dose of 82.7 Gy (standard deviation: 1.0 Gy). The dose volume constraints were fulfilled in every patient, the mean percentage volume of rectum receiving $40 \mathrm{~Gy}, 50 \mathrm{~Gy}$ and 70 Gy being equal to $44.0 \%( \pm 8.0), 34.9 \%( \pm 6.3)$ and $19.9 \%$ ( \pm 4.7), respectively, and the mean percentage volume of bladder receiving $50 \mathrm{~Gy}$ and $70 \mathrm{~Gy}$ equal to $32.7 \%( \pm 11.9)$ and $19.2 \%( \pm 8.2)$, respectively. In particular the maximum and mean dose to the rectum were $87.5 \mathrm{~Gy}$ $( \pm 1.2)$ and 42.5 Gy $( \pm 4.8)$, respectively; while the dose received by more than 1 and $5 \mathrm{cc}$ of the rectum were 85.1 Gy $( \pm 1.3)$ and 79.1 Gy $( \pm 4.3)$, respectively.

\section{Toxicity}

The IPSS questionnaire at baseline resulted in 36/39 (92\%) of asymptomatic or low symptomatic patients (IPSS score $\leq 7), 3 / 39(8 \%)$ moderate symptomatic (IPSS score 8-19), no patient was severely symptomatic (IPSS score 20-35). In our cohort, the acute side effects of radiotherapy were moderate and transient. No patient experienced G3 or G4 acute gastrointestinal (GI) or genitourinary (GU) toxicity. G2 acute GI and GU toxicity were observed in $17(44 \%)$ and $20(51 \%)$ patients, respectively (Figure 1). Fourteen patients (36\%) did not experience acute GI and 4 patients (10\%) did not experience acute GU toxicity. G2 late GI bleeding occurred in 7 of 39 patients (18\%). Both G3 and G4 late GI toxicity were seen only in one patient (2.5\%); in the first case G3 late GI toxicity was characterized by persistent bleeding treated with 4 sessions of laser coagulation, in the second case the G4 late GI toxicity was a fistula which required packing a temporary colostomy. Two patients (5\%) experienced G2 late GU toxicity, while G3 late GU toxicity characterized by urethral stricture occurred in 3 patients (8\%), two of whom had undergone 


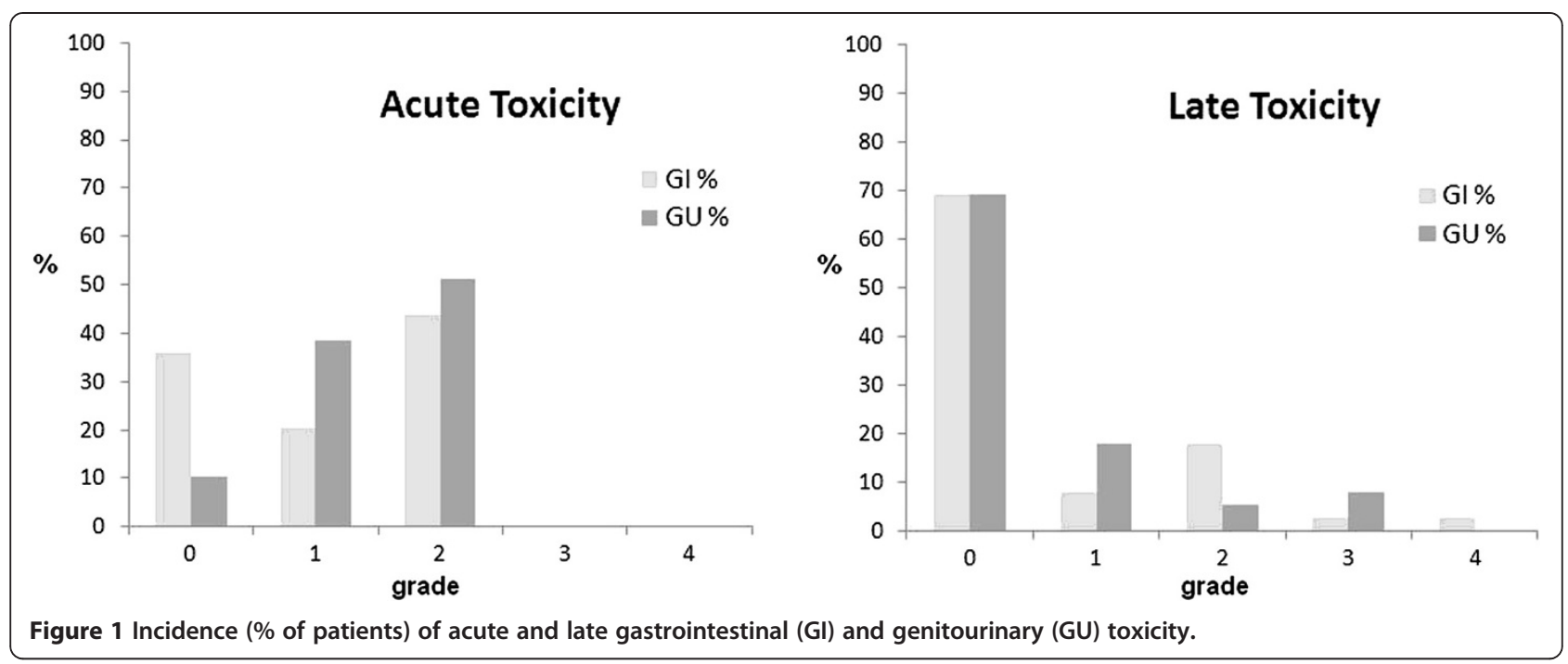

an endoscopic transurethral resection of prostate (TURP) before radiotherapy; no patient experienced G4 late GU toxicity (Figure 1 ). The actuarial analysis of $\geq \mathrm{G} 2$ late GI and GU complications is reported in Figure 2. The 5-year actuarial incidence of $\geq \mathrm{G} 2$ late GI and GU complications was $21.0 \%$ (std error $6.6 \%$ ) and $12.8 \%$ (std error $5.4 \%$ ), respectively. In Figure 3 mean dose volume histograms of the volume of rectum enclosed in the PTV are shown: a statistically significant difference was found between patients who did and did not experience late $\geq 2$ GI toxicity ( $\mathrm{p}<0.0001$ Mann-Whitney test).

\section{Biochemical control rates and biopsies}

The 5-year actuarial FFBF after ultra-high IMRT dose of $86 \mathrm{~Gy}$ at $2 \mathrm{~Gy} /$ fraction was $87 \%$ (standard error 6\%), without the use of ADT, as shown in Figure 4. Five patients (13\%) had a biochemical failure, one of these presented also a local relapse and two patients presented also distance metastasis, while 34 (87\%) did not show evidence of biochemical disease. Out of 39 patients, 22 patients refused undergoing a biopsy at 2-years post-radiotherapy. Out of 17 patients who underwent re-biopsy, 15 biopsies $(88 \%)$ resulted completely negative, $1(6 \%)$ positive and 1 (6\%) indeterminate, but both the last two patients did not show evidence of biochemical disease.

\section{Discussion}

Our study represents the first prospective trial reporting results of the highest dose escalation using doses of $86 \mathrm{~Gy}$ at $2 \mathrm{~Gy} /$ fraction, for the IMRT treatment of patients with localized intermediate-risk prostate cancer without ADT. Out of 39, 7 patients (18\%) reported G2 late GI toxicity, one patient (2.5\%) reported G3 late GI toxicity and one patient (2.5\%) reported G4 late GI toxicity. In
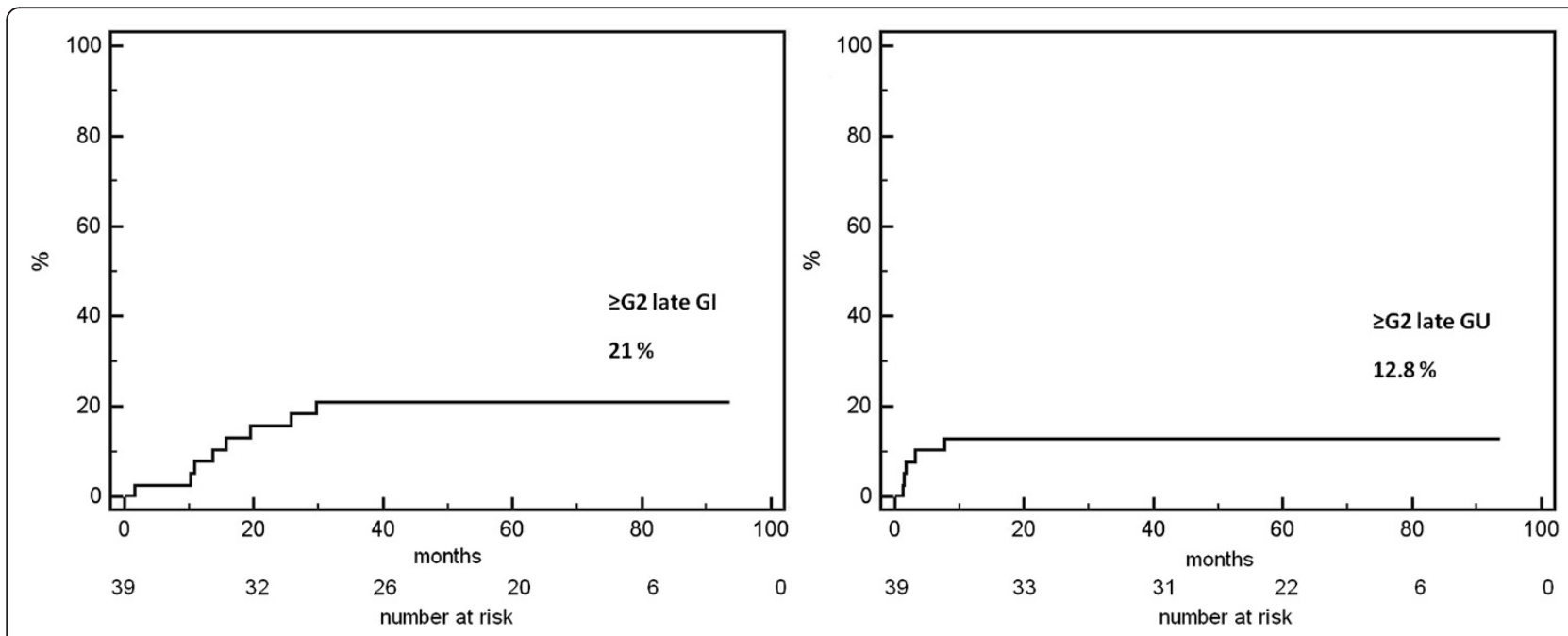

Figure 2 Actuarial incidence of $\geq \mathrm{G} 2$ late $\mathrm{Gl}$ and $\mathrm{GU}$ toxicity. 


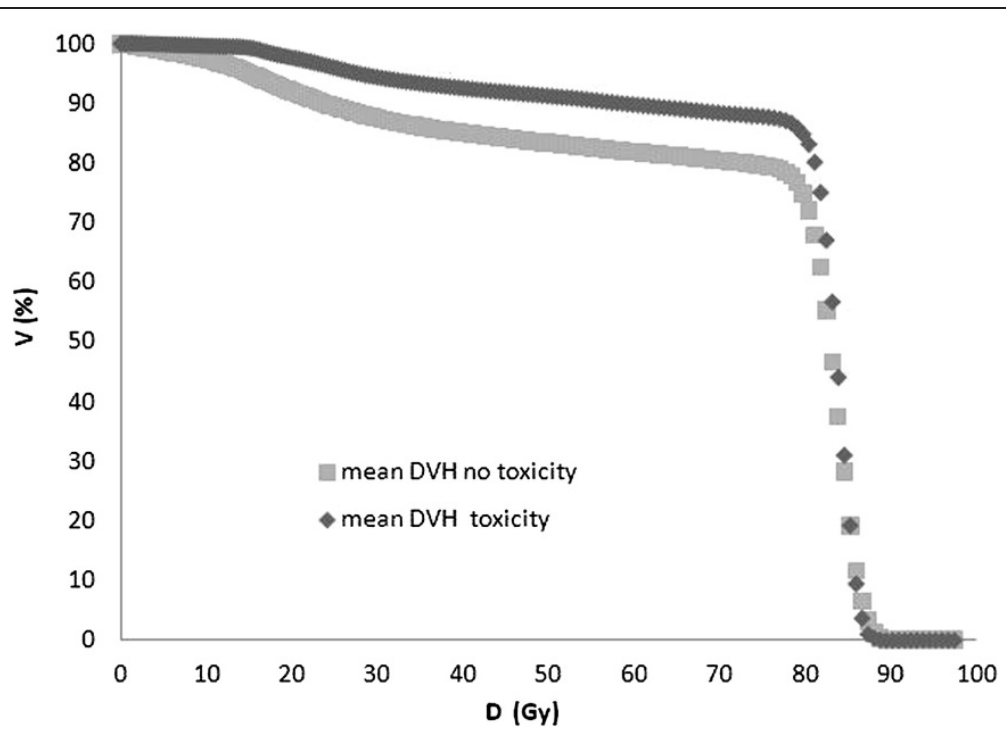

Figure 3 Mean dose volume histograms of the volume of rectum enclosed in the PTV for patients who did and did not experience late Gl toxicity.

this feasibility study, $\geq \mathrm{G} 2$ late GI toxicity was higher than expected from cases treated at our Institute with IMRT at doses of 80 Gy and from the literature [15-18]. However, the observed actuarial $\geq \mathrm{G} 2$ late GI toxicity (21\%) was lower to that found in the study RTOG 9406 conducted by Michalski et al. [29] reporting a rate of $\geq \mathrm{G} 2$ GI complication ranging from $30 \%$ to $33 \%$ for 24 months at dose level V (78 Gy) but higher than that (4\%) reported by Cahlon et al. [17]. The higher observed $\geq$ G2 late GI toxicity might be due to the lack of specific dose constraints for rectum volume within the PTV and to the fact that also seminals vesicles received the full treatment dose. In fact a statistically significant correlation was observed between dose volume histograms of the volume of rectum enclosed in the PTV and $\geq$ G2 late GI toxicity. It is worth noting that patients were enrolled in this study before the publication of Quantec [30], where it is stated that "Reducing the V75 by just $5 \%$ from $15 \%$ to $10 \%$ has a significant impact in the predicted complication probability ..." but "the proposed dose-volume constraints might be unachievable ... but every effort should be made to be as close as possible to the constraints especially in the high

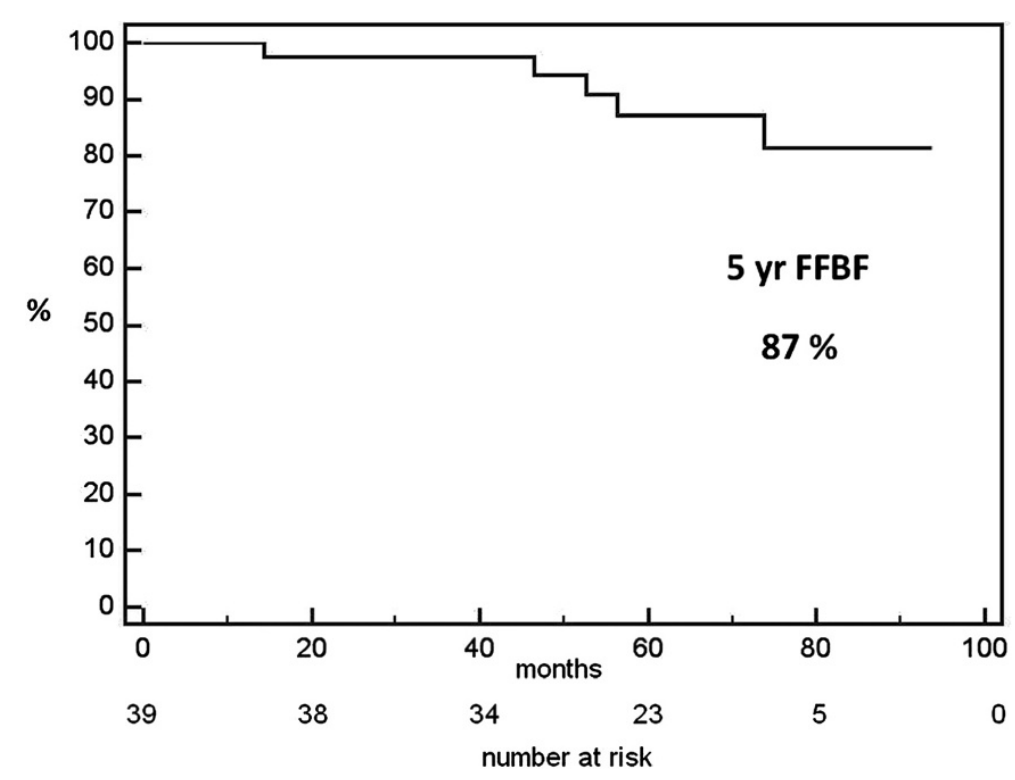

Figure 4 Freedom from biochemical failure survival. 
doses". Nevertheless, methods allowing the reduction of the PTV, such as CBCT and/or markers for IGRT, could further reduce the incidence of rectal toxicity [31,32], considering that the prostate and the anterior rectal wall, i.e. the area most susceptible to receive an high dose, cannot be seen using EPID images only. In randomized dose-escalation trials employing 3D-CRT the incidence of $\geq \mathrm{G} 2$ late GI toxicity ranged between $17 \%$ and 32\% [3-7]. This GI toxicity are similar to our results, even if in our trial higher doses were delivered. Moreover, pre-radiotherapy ADT has been reported as a protective factor for GI late toxicity due to the expected reduction of PTV volume [33].

No patients experienced G4 late GU toxicity and three patients (8\%) developed G3 late GU toxicity, two of which were previously treated for urethral stricture. The observed 5-year incidence of $\geq \mathrm{G} 2$ late GU toxicity was $12.8 \%$, which seems comparable to the 5 -year actuarial risk (of 16\%) reported by Cahlon et al. [17], and to the 3 -year actuarial risk of 19\% G2 late GU reported by Fonteyene et al., with doses between 72 Gy and 78 Gy [16]. However, comparisons of patients across study cohorts are difficult and should be interpreted with caution. In particular, the role of hormone therapy in the setting of dose escalation could introduce some bias, thus confounding the analysis, which needs to be evaluated in a randomized trial. The observed five years FFBF of $87 \%$, according to the Phoenix definition, is comparable with the results of $85 \%$ reported by Cahlon et al. [17], using a total dose of 86.4 Gy (1.8 cGy/fraction) in combination with neoadjuvant or concurrent ADT. The true role of androgen deprivation in dose escalation schedules in patients with intermediate prognosis risk is currently unknown, the fact that hormonal therapy was not used in this study did not seem to impact on the outcome, even though, more patients and a longer follow up are needed to clearly state the role of ADT. Cell killing by hormone-therapy could reduce the tumor burden, enhancing local control, and maybe decreasing the rate of distant metastases [34]. Eade et al. [9] suggested that the use of doses $>80$ Gy for localized prostate cancer results in better local control and less distant failures when compared to doses $<80 \mathrm{~Gy}$, analyzing a cohort of patients free from ADT. In this report, the authors observed a reduced risk of biochemical recurrence of $2.2 \%$ at 8 years for the addition of each Gy over $80 \mathrm{~Gy}$ and concluded that the plateau on the dose-response curve for prostate cancer lies well above $80 \mathrm{~Gy}$. Also, feasibility studies of single Institutions and some randomized trials of dose escalation showed improved results in the treatment of localized prostate cancer [1-8]; analyzing the effects of increased doses between prognostic categories, the best results are observed in the intermediate risk [3-9,15,34-36]. Even though, with a larger number of enrolled patients a multivariate analysis could better clarify the results observed, we believe that the current series demonstrates the advantage in terms of disease control of using ultra-high doses in the treatment of intermediate risk prostate cancer while the incidence of toxicity observed could be lowered by applying stricter requirements on the dose volume constraints at the interface of the rectum with the posterior portion of the prostate gland and introducing a more advanced imaging protocol, i.e. cone beam CT imaging. Moreover, authors are aware that quality of life questionnaires to investigate treatment effects as reported by patients could have added information to the overall rating of treatment results; for this reason, since then, great effort has been made to introduce in our policy also this additional tool of evaluation.

\section{Conclusion}

Our results proved to be good in terms of FFBF without using ADT in intermediate-risk prostate cancer patients. Although a longer follow up and more patients are needed to assert that ultra-high dose escalation using IMRT could be a viable alternative to lower doses plus ADT, though manifesting an increase of $\geq G 2$ late GI rate, the data reported in this study seem promising. Finally, even if the inclusion criteria of freedom from ADT is a very limiting factor for the accrual rate in the intermediate risk patient cohort because ADT is often a standard therapeutic strategy, we believe that only a randomized study can accurately compare outcomes between different doses in dose escalation schedules.

\section{Abbreviations}

GI: Gastrointestinal; GU: Genitourinary; FFBF: Freedom from biochemical failure; IMRT: Intensity modulated radiation therapy; ADT: Androgen deprivation therapy; DMFS: Distant metastasis-free survival; CSS: Cancerspecific survival; 3D-CRT: Three-dimensional conformal radiation therapy; CTV: Clinical target; PTV: Planning target volume; EPID: Electronic portal imaging device; DRR: Digitally reconstructed radiography; DRE: Rectal examination; TURP: Transurethral resection of prostate.

\section{Competing interests}

The authors hereby declare that they do not have any competing interest in this study.

\section{Authors' contribution}

MGP, GA, VL and BS conceived and designed the study. MGP, VL, BS, SG, SA, $\mathrm{Gl}$, PP collected and assembled the data, VL performed the statistical analysis, MGP and VL wrote the manuscript. LS and GA gave support in the final drafting of the paper. All authors read and approved the final manuscript.

\section{Author details}

'Department of Radiation Oncology, Regina Elena National Cancer Institute, Rome, Italy. 'Laboratory of Medical Physics and Expert Systems, Regina Elena National Cancer Institute, Rome, Italy.

Received: 23 September 2013 Accepted: 3 December 2013 Published: 13 December 2013

\section{References}

1. Hanks GE, Hanlon AL, Schultheiss TE, Pinover WH, Movsas B, Epstein BE, Hunt MA: Dose escalation with 3D conformal treatment: five year outcomes, treatment optimization, and future directions. Int J Radiat Oncol Biol Phys 1998, 41(3):501-510. 
2. Zelefsky MJ, Leibel SA, Gaudin PB, Kutcher GJ, Fleshner NE, Venkatramen ES, Reuter VE, Fair WR, Ling CC, Fuks Z: Dose escalation with threedimensional conformal radiation therapy affects the outcome in prostate cancer. Int J Radiat Oncol Biol Phys 1998, 41(3):491-500.

3. Zietman AL, DeSilvio ML, Slater JD, Rossi CJ Jr, Miller DW, Adams JA, Shipley WU: Comparison of conventional-dose vs high-dose conformal radiation therapy in clinically localized adenocarcinoma of the prostate: a randomized controlled trial. JAMA 2005, 294:1233-1239.

4. Dearnaley DP, Sydes MR, Graham JD, Aird EG, Bottomley D, Cowan RA, Huddart RA, Jose CC, Matthews JH, Millar J, Moore AR, Morgan RC, Russell JM, Scrase CD, Stephens RJ, Syndikus I, Parmar MK, RT01 collaborators: Escalated-dose versus standard-dose conformal radiotherapy in prostate cancer: first results from the MRC RT01 randomised controlled trial. Lancet Oncol 2007, 8:475-487.

5. Kuban DA, Tucker SL, Dong L, Starkschall G, Huang EH, Cheung MR, Lee AK, Pollack A: Long-term results of the M.D.Anderson randomized doseescalation trial for prostate cancer. Int J Radiat Oncol Biol Phys 2008, 70:67-74.

6. Al-Mamgani A, van Putten WL, van der Wielen GJ, Levendag PC, Incrocci L: Dose escalation and quality of life in patients with localized prostate cancer treated with radiotherapy: long-term results of the Dutch randomized dose-escalation trial (CKTO 96-10 trial). Int J Radiat Oncol Biol Phys 2011, 79(4):1004-1012.

7. Beckendorf V, Guérif S, Le Prisé E, Cosset JM, Lefloch O, Chauvet B, Salem N, Chapet O, Bourdin S, Bachaud JM, Maingon P, Lagrange JL, Malissard L, Simon JM, Pommier P, Hay MH, Dubray B, Luporsi E, Bey P: 70 Gy vs 80 Gy in localized prostate cancer: 5-year results GETUG 06 randomized trial. Int J Radiat Oncol Biol Phys 2011, 80:1056-1063.

8. Shipley WU, Verhey $\amalg$, Munzenrider JE, Suit HD, Urie MM, McManus PL, Young RH, Shipley JW, Zietman AL, Biggs PJ, et al: Advanced prostate cancer: the results of a randomized comparative trial of high dose irradiation boosting with conformal protons compared with conventional dose irradiation using photons alone. Int J Radiat Oncol Biol Phys 1995, 32(1):3-12.

9. Eade TN, Hanlon AL, Horwitz EM, Buyyounouski MK, Hanks GE, Pollack A: What dose of external-beam radiation is high enough for prostate cancer? Int J Radiat Oncol Biol Phys 2007, 68:682-689.

10. Hanks GE, Hanlon AL, Epstein B, Horwitz EM: Dose response in prostate cancer with 8-12 years' follow-up. Int J Radiat Oncol Biol Phys 2002, 54:427-435.

11. Jacob R, Hanlon AL, Horwitz EM, Movsas B, Uzzo RG, Pollack A: The relationship of increasing radiotherapy dose to reduced distant metastases ad mortality in men with prostate cancer. Cancer 2004, 100:538-543.

12. Pollack A, Hanlon AL, Horwitz EM, Feigenberg SJ, Uzzo RG, Hanks GE: Prostate cancer radiotherapy dose response: an update of the Fox Chase experience. J Urol 2004, 171:1132-1136.

13. Zelefsky MJ, Chan H, Hunt M, Yamada Y, Shippy AM, Amols H: Long-term outcome of high dose intensity modulated radiation therapy for patients with clinically localized prostate cancer. J Urol 2006, 176(4 Pt 1):1415-1419.

14. Michalski JM, Bae K, Roach M, Markoe AM, Sandler HM, Ryu J, Parliament MB, Straube W, Valicenti RK, Cox JD: Long-term toxicity following 3D conformal radiation therapy for prostate cancer from the RTOG 9406 phase I/II dose escalation study. Int J Radiat Oncol Biol Phys 2010, 76:14-22.

15. De Meerleer GO, Fonteyne VH, Vakaet L, Villeirs GM, Denoyette L, Verbaeys A, Lummen N, De Neve WJ: Intensity-modulated radiation therapy for prostate cancer: late morbidity and results on biochemical control. Radiother Oncol 2007, 82:160-166.

16. Fonteyne V, Villeirs G, Lumen N, De Meerleer G: Urinary toxicity after high dose intensity modulated radiotherapy as primary therapy for prostate cancer. Radiother Oncol 2009, 92:42-47.

17. Cahlon O, Zelefsky MJ, Shippy A, Chan H, Fuks Z, Yamada Y, Hunt M, Greenstein S, Amols H: Ultra-high dose (86.4Gy) IMRT for localized prostate cancer: toxicity and biochemical outcomes. Int J Radiat Oncol Biol Phys 2008, 71:330-337.

18. Zelefsky MJ, Fuks Z, Hunt M, Yamada Y, Marion C, Ling CC, Amols H, Venkatraman ES, Leibel SA: High-dose intensity modulated radiation therapy for prostate cancer: early toxicity and biochemical outcome in 772 patients. Int J Radiat Oncol Biol Phys 2002, 53(5):1111-1116.

19. Landoni V, Saracino B, Marzi S, Gallucci M, Petrongari MG, Chianese E, Benassi M, laccarino G, Soriani A, Arcangeli G: A study of the effect of setup errors and organ motion on prostate cancer treatment with IMRT. Int J Radiat Oncol Biol Phys 2006, 65:587-594.
20. Mundt AJ, Lujan AE, Rotmensch J, Waggoner SE, Yamada SD, Fleming G, Roeske JC: Intensity-modulated whole pelvic radiotherapy in women with gynecologic malignancies. Int J Radiat Oncol Biol Phys 2002, 52:1330-1337.

21. Portelance L, Chao KS, Grigsby PW, Bennet H, Low D: Intensity-modulated radiation therapy (IMRT) reduces small bowel, rectum and bladder dose in patients with cervical cancer receiving pelvic and para-aortic irradiation. Int J Radiat Oncol Biol Phys 2001, 51:261-266.

22. Mundt AJ, Mell LK, Roeske JC: Preliminary analysis of chronic gastrointestinal toxicity inGynecology patients treated with intensity-modulated whole pelvic radiation therapy. Int J Radiat Oncol Biol Phys 2003, 56:1354-1360.

23. Huang EH, Pollack A, Levy L, Starkschall G, Dong L, Rosen I, Kuban DA: Late rectal toxicity: dose-volume effects of conformal radiotherapy for prostate cancer. Int J Radiat Oncol Biol Phys 2002, 54:1314-1321.

24. Sanguineti G, Agostinelli S, Foppiano F, Franzone P, Garelli S, Marcenaro M, Orsatti M, Vitale V: Adjuvant androgen deprivation impacts late rectal toxicity after conformal radiotherapy of prostate carcinoma. $\mathrm{Br} J$ Cancer 2002, 86:1843-1847.

25. Arcangeli G, Saracino B, Gomellini S, Petrongari MG, Arcangeli S, Sentinelli S, Marzi S, Landoni V, Fowler J, Strigari L: A prospective phase III randomized trial of hypofractionation versus conventional fractionation in patients with high-risk prostate cancer. Int J Radiat Oncol Biol Phys 2010, 78(1):11-18.

26. Cancer Therapy Evaluation Program, Common Terminology Criteria for Adverse Events, Version 3.0, DCTD, NCl, NIH, DHHS: (http://ctep.cancer.gov), Publish Date: August 9, 2006.

27. Roach M 3rd, Hanks G, Thames H Jr, Schellhammer P, Shipley WU, Sokol GH, Sandler H: Defining biochemical failure following radiotherapy with or without hormonal therapy in men with clinically localized prostate cancer: recommendations of the RTOG-ASTRO Phoenix Consensus Conference. Int J Radiat Oncol Biol Phys 2006, 65:965-974.

28. Barry MJ, Fowler FJ Jr, O'Leary MP, Bruskewitz RC, Holtgrewe HL, Mebust WK, Cockett AT: The American Urological Association symptom index for benign prostatic hyperplasia. The Measurement Committee of the American Urological Association. J Urol 1992, 148:1549-1557.

29. Michalski JM, Winter K, Purdy JA, Parliament M, Wong H, Perez CA, Roach M, Bosch W, Cox JD: Toxicity after three-dimensional radiotherapy for prostate cancer on RTOG 9406 dose level V. Int J Radiat Oncol Biol Phys 2005, 62:706-713.

30. Michalski J, Gay H, Jackson A, Tucker S, Deasy J: Radiation dose-volume effects in radiation-induced rectal injury. Int J Radiat Oncol Biol Phys 2010, 76(3 Supplement):S123-S129.

31. Martin JM, Bayley A, Bristow R, Chung P, Gospodarowicz M, Menard C, Milosevic M, Rosewall T, Warde PR, Catton CN: Image guided dose escalated prostate radiotherapy: still room to improve. Radiat Oncol 2009, 4:50.

32. Zelefsky MJ, Kollmeier M, Cox B, Fidaleo A, Sperling D, Pei X, Carver B, Coleman J, Lovelock M, Hunt M: Improved clinical outcomes with high-dose image guided radiotherapy compared with non-IGRT for the treatment of clinically localized prostate cancer. Int J Radiat Oncol Biol Phys 2012, 84(1):125-129.

33. Zelefsky MJ, Harrison A: Neoadjuvant androgen ablation prior to radiotherapy for prostate cancer: reducing the potential morbidity of therapy. Urology 1997, 49(3A Suppl):38-45.

34. Pollack A, Hanlon AL, Movsas B, Hanks GE, Uzzo R, Horwitz EM: Biochemical failure as a determinant of distant metastasis and death in prostate cancer treated with radiotherapy. Int J Radiat Oncol Biol Phys 2003, 57:19-23.

35. Zelefsky MJ, Yamada Y, Fuks Z, Zhang Z, Hunt M, Cahlon O, Park J, Shippy A: Long-term results of conformal radiotherapy for prostate cancer: impact of dose escalation on biochemical tumor control and distant metastases-free survival outcomes. Int J Radiat Oncol Biol Phys 2008, 71:1028-1033.

36. Kuban DA, Thames HD, Levy LB, Horwitz EM, Kupelian PA, Martinez AA Michalski JM, Pisansky T: Long-term multi-istitutional analysis of stage T1-T2 prostate cancer treated with radiotherapy in the PSA era. Int J Radiat Oncol Biol Phys 2003, 57:915-928.

doi:10.1186/1756-9966-32-103

Cite this article as: Petrongari et al:: Dose escalation using ultra-high dose IMRT in intermediate risk prostate cancer without androgen deprivation therapy: preliminary results of toxicity and biochemical control. Journal of Experimental \& Clinical Cancer Research 2013 32:103. 